\title{
Eclampsia: Feto-Maternal Outcomes in A Tertiary Care Centre in Eastern Nepal
}

\author{
Sita Ghimire ${ }^{1}$ \\ 'Department of Obstetrics and Gynaecology. Nobel Medical College, Biratnagar, Nepal.
}

\section{ABSTRACT}

Introduction: Eclampsia is a preventable and treatable cause of maternal morbidity and mortality with poor feto-maternal outcome in developing countries. Despite development in the level of health education expertise in human resources and institutional obstetric care in our country, the delay in early recognition of the problem, transportation to proper health facility and getting proper expert care are major hurdles to reduce complications. Therefore we decided to study feto-maternal outcomes in our setting.

Methods: A retrospective cross-sectional hospital based study carried out in Nobel Medical College, Biratnagar, from $17^{\text {th }}$ June 2014 to $16^{\text {th }}$ June 2015. Details and data obtained from Medical Record Section were analysed. All patients with eclampsia were included and fetomaternal outcomes measured in terms of complications. Simple descriptive statistical method was applied for analysis.

Results: Among 8,066 deliveries, 112 had eclampsia with incidence of 13.8/1000 deliveries. Majority $(41 \%)$ were of $<19$ years of age. Above $90 \%$ were unbooked. Aoubt $63.4 \%$ were primiparas and $83 \%$ had antepartum eclampsia. Eclamptic fits were more common (41.6\%) in 37-40 weeks period of gestation. Fits to delivery interval was more than six hours in $89.1 \%$ women and $69.3 \%$ women underwent caesarean delivery. About $18.9 \%$ women developed eclampsia related complications. Common causes of maternal deaths (5.36\%) were pulmonary edema, aspiration pneumonia, cerebrovascular accidents and HELLP syndrome. Perinatal death was nine percent.

Conclusions: Although the obstetric care facilities are improving with time, the feto-maternal outcomes are still poor in our country. Therefore early recognition and proper management are vital to tackle this challenge.

Keywords: eclampsia; fetomaternal outcomes; retrospective analysis.

\section{INTRODUCTION}

Eclampsia is a preventable and treatable cause of maternal morbidity and mortality with poor fetomaternal outcomes in developing countries. ${ }^{1}$ Eclampsia is rare in the developed world with good facilities. ${ }^{2}$ Despite the relative development in the level of women health education, expertise in human resources and institutional obstetric care in our country, still the delay in early recognition of the problem, transportation to proper health facility and getting proper expert care in time are major hurdles to reduce complications. We hypothesize that the burden of eclampsia in our tertiary centre is still high. Therefore we decided to study fetomaternal outcomes in our setting.

Correspondence: Dr. Sita Ghimire, Department of Obstetrics and Gynaecology. Nobel Medical College, Biratnagar, Nepal. Email: sitap661@gmail.com, Phone: +977-9852033022. 


\section{METHODS}

A retrospective cross-sectional hospital based study that will be carried out in Nobel Medical College, Biratnagar, a tertiary care centre, in Eastern region. Detail analysis of the records of the patients with eclampsia was carried out admitted from $17^{\text {th }}$ June 2014 to $16^{\text {th }}$ June 2015 from Medical Record Section. All patients with eclampsia were included and feto maternal outcomes were measured in the form of complications and death. The study was approved by the Institutional Review Committee (IRC) of Nobel Medical College, Biratnagar authorized by Nepal Health Research Council (NHRC). Collected data was entered into Microsoft Exel. The data was analysed using SPSS version 14.0. Simple descriptive statistical methods were applied for analysis.

\section{RESULTS}

During one year duration, among 8066 deliveries, 112 had eclampsia with incidence of $13.8 / 1000$ deliveries, $1.38 \%$. Forty one percent were of $<19$ years of age and majority were young (78\%) of less than 24 years. More than $90 \%$ were unbooked in our centre but most of them had their antenatal check care in sub health post, health post and primary health centres. In spite of this, they were late to come to our centre. Most $(64 \%)$ were primiparas followed by multiparas $(33.9 \%)$ and $83 \%$ had antepartum eclampsia. Eclamptic fits were more common $(41.6 \%)$ in $37-40$ weeks period of gestation (POG) followed by (36.6\%) 34-37 weeks of POG. It occurred rarely in $<34$ weeks POG. Fits to delivery interval was more than six hours in nearly $90 \%$ women. Most $(61.4 \%)$ have fits to delivery interval was 6-12 hours. Nearly $70 \%$ women underwent caesarean delivery. Nearly $20 \%$ women developed eclampsia related complications like cerebral edema, renal failure, HELLP syndrome, pulmonary edema and psychosis. Thirty percent of the women needed intensive care (ICU). Common causes of maternal deaths $(5.36 \%)$ were hemolysis, elevated liver enzyme and low platelets (HELLP) syndrome and pulmonaruy edema. Among two cerebrovascular accident patients, one died. Two of three pulmonary edema patients died. Patients with psychosis and renal failure recovered completely. Pulmonary aspiration caused death of one while two of four HELLP syndrome died. Perinatal complications included preterm baby $(42.6 \%)$ and low birth weight(39.6\%).32.6\% babies have APGAR score of $<7$ and of which $69.6 \%$ needed neonatal intensive care(NICU).Six were fresh stillborn while three were macerated. Perinatal death was nine percent.

\begin{tabular}{|c|c|}
\hline Age in years & n (\%) \\
\hline Less than 19 & $46(41.1)$ \\
\hline $20-24$ & 41 (36.6) \\
\hline $25-29$ & $14(12.5)$ \\
\hline $30-34$ & $8(7.1)$ \\
\hline More than 35 & $3(2.7)$ \\
\hline \multicolumn{2}{|c|}{ Parity distribution } \\
\hline Primipara & $71(63.4)$ \\
\hline Multipara & 38 (33.9) \\
\hline Grand Multipara & $3(2.7)$ \\
\hline No antenatal care & 109 (97.32) \\
\hline Antenatal care & $3(2.68)$ \\
\hline Total & $112(100)$ \\
\hline
\end{tabular}

Almost all of the women did not receive antenatal care in tertiary care centre. But most $68(60.71 \%)$ of them had their antenatal care in sub health post, health post and primary health centers that was not at par the standard requirement with poor documentation.

\begin{tabular}{|ll|}
\hline Table 2. Types of eclampsia. \\
\hline Eclampsia & \multicolumn{1}{c|}{$\mathrm{n} \mathrm{( \% )}$} \\
Antepartum & $93(83)$ \\
Intrapartum & $8(7.1)$ \\
Postpartum & $11(9.8)$ \\
Total & $112(100)$ \\
\hline
\end{tabular}

Table 3. Period of gestation and fits to delivery interval.

\begin{tabular}{|ll|}
\hline Period of gestation & $\mathrm{n}(\%)$ \\
Less than 34 weeks & $6(5.9)$ \\
$34-37$ & $37(36.6)$ \\
$37-40$ & $42(41.6)$ \\
Post dated & $16(15.8)$ \\
Total $\quad$ Fits-delivery interval \\
\\
Less than 6 hours & $11(101(100)$ \\
$6-12$ hours & $62(61.4)$ \\
$12-24$ hours & $28(27.7)$ \\
More than 24 hours & $0(0.0)$ \\
Total & $101(100)$ \\
\hline
\end{tabular}

Almost all women delivered within 24 hours of the convulsion. 


\begin{tabular}{|ll|}
\hline Table 4. Mode of care. & \\
\hline Mode of Care & $\mathrm{n}(\%)$ \\
Intensive care (ICU) & $33(29.46)$ \\
Ward care & $79(69.54)$ \\
Admission $<7$ days & $53(47.32)$ \\
Admission $>7$ days & $59(52.67)$ \\
Mode of delivery & \\
Normal vaginal delivery & $27(26.7)$ \\
Vaccum/ Forceps & $4(4.0)$ \\
Cesarean section & $70(69.3)$ \\
Total & $101(100)$ \\
\hline
\end{tabular}

One third of the patients required special care and most patients stayed in hospital for more than a week. Majority underwent emergency cesarean section.

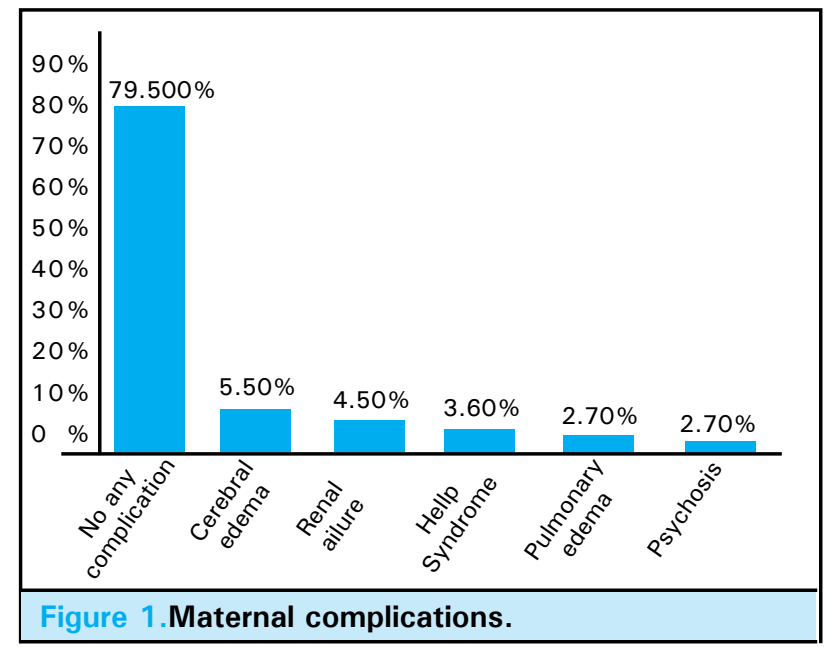

Nearly $20 \%$ patients developed some forms of complications. Six maternal deaths occurred with CFR $5.3 \%$, pulmonary complication being the most common cause. Nearly half of the patients died because of pulmonary complications.

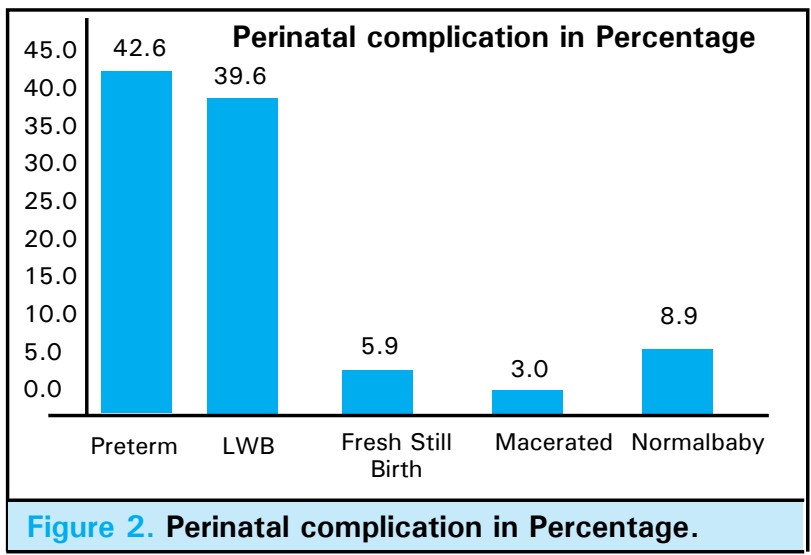

More than $90 \%$ of the babies had complications from LBW to preterm and perinatal death was nine percent.

\section{DISCUSSION}

During the period of one year $\left(17^{\text {th }}\right.$ June 2014 to $16^{\text {th }}$ June 2015), among 8066 deliveries, 112 had eclampsia with incidence of $13.8 / 1000$ deliveries and $1.38 \%$. The different incidence of eclampsia has been reported as $0.29,{ }^{3} 0.24,{ }^{4} 0.14,{ }^{5} 0.09,{ }^{6}$ Kathmandu, $0.40^{7}$ in Western Nepal, $0.66,{ }^{8}$ in Eastern Nepal and 1.38 in present study, whereas, $1.0,{ }^{9} 3.20^{10}$ in the India and $0.05^{11}$ in the UK.

Our study revealed higher figure than $0.29 \%$ in maternity hospital by Chaudhary $\mathrm{P}$ et $\mathrm{al}^{3}{ }^{3} 0.24 \%$ in Patan Hospital by Acharya G et al, ${ }^{4} 0.14 \%$ in maternity hospital by Shakya B et al, $0.09 \%$ in Institute of medicine Teaching hospital by Gautam SK et al, ${ }^{6}$ all studies from Kathmandu and in Far western region, Bheri Zonal Hospital $0.4 \%$ by Dhakal G et al, ${ }^{7}$ Eastern region BPKIHS $0.66 \%$ by Rayamajhi $A K$ et al, ${ }^{8}$ an east Indian study $1 \%$ by Sunita $\mathrm{TH}$ et $\mathrm{al}^{,}{ }^{9}$ in the United Kingdom(UK) $0.05 \%$ by Douglas KA et al ${ }^{11}$ but lower than another Indian study $3.2 \%$ by Singh $S$ et al. ${ }^{10}$ Detail analysis of the above studies reveals great variation in incidence and that the incidence of eclampsia depends upon multiple factors. The incidence is determined by temporal factor, socioeconomic development, age at marriage, maturation and modernization of the health facility, concentration of the cases in single centre especially from Safe motherhood programme, takingno-risk policy and referring the serious eclamptic patients to medical colleges. Similarly, geographical and racial factors also thought to play role in this high incidence that is yet to be further explored. Most of the time it becomes really difficult to count the factors that directly or indirectly come into play, the only thing is that the predominant and modifiable factors are to be taken into account when formulating plan and policies. As far as explanation for our higher figure of incidence is concerned, our centre is in the border of Nepal and India, where early marriage is common; people have poor socioeconomic status and antenatal care in vast majority of the women. We have also operated Safe motherhood programme, we cover large catering areas in the Eastern region. We assume that the cases are concentrated in our centre. The incidence in Kathmandu valley is decreasing with time probably reflecting development in socioeconomic status and maturation of health facilities, this trend is further verified by very low incidence in UK even 20 years back reflecting degree of development lowering the incidence of eclampsia. Therefore overall development of the society as a whole is more important than one or two factors in isolation for the reduction of the incidence of eclampsia and its complications.

Eclampsia is more common (85\%) in young women 
and $(63.4 \%)$ primigravidas in our study which is nearly comparable to studies by Sunita $\mathrm{TH}$ et $\mathrm{al}^{9}$ and Kaur $\mathrm{P}$ et al. ${ }^{12}$ Almost all $(97 \%)$ of the patients did not receive antenatal care from our centre and $61 \%$ of them received some forms of antenatal care from peripheral government facilities but their level of care and documentation were not as per the standard of care. It seems that awareness on the part of the patient and health care providers is not adequate for early referral and proper care. Gautam SK et $\mathrm{al}^{6}$ reported that $98.4 \%$ of their patients received antenatal care and incidence of eclampsia in their study was low. Surprisingly, a study done by Manandhar BL showed that antenatal care could not reduce the risk of severe preeclampsia/eclampsia. Most of our patients have antepartum eclampsia and which occurred at term pregnancy in most patients. Our findings were correlated with studies done by Jha $\mathrm{R}$ et $\mathrm{al}^{14}$ and Kaur P. ${ }^{12}$ Only $10.9 \%$ of the patients delivered within 6 hours of convulsion which is lower $(29 \%)$ than another study Sunita $\mathrm{TH}$ et $\mathrm{al}^{9}$ and $17.02 \%$ in $<5$ hours by Chaudhary $\mathrm{P}$ et al. ${ }^{3}$ Early termination of pregnancy could have been better but home-to-hospital time was long probably because of logistic and other constraints including transportation. Vast majority $(69.3 \%)$ of our patients were delivered by cesarean section which is higher than other studies $55.31 \%$ by Chaudhary $P$ et $\mathrm{al}^{3} 45 \%$ by Sunita $\mathrm{TH}$ et $\mathrm{al}^{9}$ in but lower than the other study by Gautam SK et $\mathrm{al}^{6}$ where all eclamptic patients underwent caesarean section. The rate of our cesarean delivery was high probably because of late presentation to the centre. Many $29.46 \%$ patients required intensive care and many required special sick-patient care and $52.67 \%$ patients were admitted in hospital for more than a week, $19.5 \%$ of the patients developed complications that is higher than a recent study in Kathmandu $7.22 \%$ Gautam SK et al it probably reflects the good health care and transportation facility in Kathmandu. Common complications were related to pulmonary, nervous system and bleeding in our study which is corroborated with findings with an Indian study. ${ }^{9}$ Our maternal mortality rate was $5.35 \%$ and cardiopulmonary and HELLP syndrome were most common cause of death and another study ${ }^{5}$ shows $4.4 \%$ maternal deaths because of cardiopulmonary complications. Another study in India showed maternal mortality rate of $4 \% .^{9}$ The different types of complications can only be managed with involvement of different sub-specialties. This scenario reflects the expert level of care and huge economic burden, these patients use even in tertiary centre.

Also we assume that the early phase development of human resources and health facilities which are not at par the requirement for managing eclampsia in the periphery than in centre may be the cause of low maternal mortality in Kathmandu. Of the 101 babies delivered only nine percent were normal, others have several complications like preterm, low birth weight and still birth. $32.6 \%$ of newborn have APGAR score of $<7$ of them $69.69 \%$ percent newborn required neonatal intensive care. Our study showed perinatal mortality of $27 \%, 21 \%$ in study by Rayamajhi AK et al, ${ }^{8} 44 \%$ by Kaur $P$ et al, ${ }^{12}$ Khanum $M$ et al (38\%). The perinatal mortality is very high in our and other studies which reflect late arrival to the centre including other complications of eclampsia. Perinatal mortality can be reduced by early intervention and good neonatal care services which is prevalent in developed countries having very low perinatal mortality rate. Although it is a retrospective study where proper recording of data may be lacking it still gave us tremendous information. In summary we conclude that the eclampsia continues to be the most important cause of maternal and perinatal morbidity and mortality in eastern Nepal. These above findings suggest that the lack of proper antenatal care, low socioeconomic status, a lack of awareness of early recognition, referral and prompt treatment of the eclampsia in the community are important issues. Proper health education and public awareness by which eclamptic patients seek timely medical care should be promoted at all level of community.

\section{ACKNOWLEDGEMENTS}

I would like to extend my sincere gratitude to all those who helped me in completing this study especially all patients, technical staffs Medical Record Department, Head of the department of obstetrics and gynecology and Managing director, Nobel Medical college and Teaching Hospital, Biratnagar.

\section{REFERENCES}

1. Pradhan A, Subedi BK, Barnett S, et al. Nepal Maternal Mortality and Morbidity study 2008/2009.Ramsah path Kathmandu Nepal: Family Health Divison,Department of Health Services, Ministry of Health and Population,Government of Nepal, 2010 (www.nepal usaid. gov/downloads/all-downloads/category/1-health-andfamily-planning.html) accessed Feb 52016
2. Chien PF, Khan KS, Arnott N, et al. Magnesium sulphate in the treatment of the eclampsia and preeclampsia: an overview of the evidence from randomized controlled trials. Br J Obstet Gynecol. 1996;103:1085-91.

3. Chaudhary P. Eclampsia: a hospital based retrospective study. Kath Univ Med J. 2002;1(4):237-41. 
4. Acharya G, Schultz S: Eclampsia in Patan hospital: A two year retrospective study. JNMA. 1991;29:254-8.

5. Shakya B, Vaidya A. Overview of eclampsia at a tertiary care hospital. NJOG. 2013;8(2):46-9.

6. Gautam (Bhattarai) SK, Paudel K, Silwal K. Management and Outcome of Pre eclampsia/Eclampsia among patient admitted in maternity ward in tertiary hospital. J Inst Med. 2013;35:30-7.

7. Dhakal G, Subedi M, Paudel K. Magnesium Sulphate in Management of Severe Pre-eclampsia and Eclampsia. J Nepal Health Res Counc. 2012;10(21):113-7.

8. Rayamajhi AK, Uprety D, Agrawal A, Pokhrel H. Fetomaternal outcomes in eclampsia. JNMA. 2003;42:341-5.

9. Sunita TH, Rathnamala MD. Eclampsia in a teaching hospital:incidence,clinical profile and response to magnesium sulfate by Zuspan regimen. J Dental Med Sci. 2013;4:1-5
10. Singh S, Bahera AK. Eclampsia in Eastern India: Incidence, demographic profile and response to three different anticonvulsant regimen of magnesium sulfate. The Int J Gynecol Obstet. 2011;15:1-7.

11. Douglas KA, Redman CW. Eclampsia in United Kingdom. Brit Med J. 1994;309(6966):1395-400.

12. Kaur P. A clinical study on eclampsia in a referral hospital. J South Asian Feder Obst Gynae. 2012;4(2):113-5.

13. Manandhar BL, Chongstuvivatwong V, Greater A. Antenatal care and severe eclampsia and preeclampsia in Kathmandu valley. J Chitwan Med Col. 2013;3(6):43-7.

14. Jha R, Verma S, Jha SK. Eclampsia in Janakpur Zonal hospital ,Nepal:Favourable outcome with Magnesium Sulphate. N J Obstet Gynecol. 2007;2:16-9.

15. Khanum M, Asraf F, Sahrin H. A clinical study of 100 cases of eclampsia in rajsahi medical college and hospital. TAJ. 2004;17(2):80-3. 